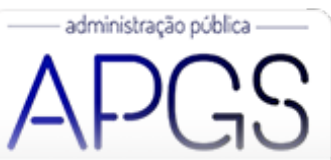

Administração Pública e Gestão Social ISSN: 2175-5787

apgs@ufv.br

Universidade Federal de Viçosa

Brasil

\title{
O Dark Side da Digitalização na Era do Capitalismo de Vigilância: Um estudo dos Termos de Consentimento da Uber à Luz da Legislação Brasileira
}

Ressetti Pinheiro Marques Vianna, Fernando; Vianna, Juliana; Kanashiro Meneghetti, Francis

O Dark Side da Digitalização na Era do Capitalismo de Vigilância: Um estudo dos Termos de Consentimento da Uber à Luz da Legislação Brasileira

Administração Pública e Gestão Social, vol. 13, núm. 4, 2021

Universidade Federal de Viçosa, Brasil

Disponible en: https://www.redalyc.org/articulo.oa?id=351568433007

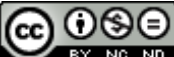

Esta obra está bajo una Licencia Creative Commons Atribución-NoComercial-SinDerivar 3.0 Internacional. 


\title{
O Dark Side da Digitalização na Era do Capitalismo de Vigilância: Um estudo dos Termos de Consentimento da Uber à Luz da Legislação Brasileira
}

\begin{abstract}
The Dark Side of Digitization in the Age of Surveillance Capitalism: A Study of Uber Consent Terms in the Light of Brazilian Legislation

El lado oscuro del escaneo en la era del capitalismo de la vigilancia: un estudio de los términos de consentimiento de Uber a la luz de la legislación brasileña
\end{abstract}

\author{
Fernando Ressetti Pinheiro Marques Vianna \\ Universidade Tecnológica Federal do Paraná - UTFPR, \\ Brasil \\ fvianna2009@hotmail.com
}

Juliana Vianna

Universidade Positivo, Brasil

falecomajuly@hotmail.com

Francis Kanashiro Meneghetti

Universidade Tecnológica Federal do Paraná, Brasil

francis@professores.utfpr.edu.br

Redalyc: https://www.redalyc.org/articulo.oa? id $=351568433007$

Recepción: 01 Octubre 2020

Aprobación: 06 Mayo 2021

Publicación: 01 Octubre 2021

\section{Resumo:}

Objetivo da pesquisa: Analisamos os tipos de más-condutas que compõem os termos de consentimento de uma organização digitalizada, na era do capitalismo de vigilância, e a conduta do Estado em relação a tais práticas.

Enquadramento teórico: $\mathrm{O}$ artigo é desenvolvido a partir de uma perspectiva crítica amparada pelas teorias do dark sidedas organizações e do capitalismo de vigilância. Justifica-se tal opção pela relação de causa e efeito entre o chamado capitalismo de vigilância e as práticas caracterizadas como má-conduta pela teoria do darkside das organizações.

Metodologia: Adotou-se o método de análise documental, por meio do qual analisamos o conteúdo dos Termos de Consentimento da Uber e das Leis n. 12.965 de 2014 ("Marco Civil da Internet") e n. 13.709 de 2018 (Lei Geral de Proteção de Dados).

Resultados: Verificou-se que os termos de consentimento da Uber conflitam com as leis em mais de setenta pontos e obscurecem as práticas de expropriação de dados, caracterizando uma má conduta da organização. A legislação criada para proteger o usuário e seus dados tem sua vigência sistematicamente prorrogada, protegendo as organizações do capitalismo de vigilância e deixando os usuários vulneráveis.

Originalidade: $\mathrm{O}$ artigo amplia os estudos sobre a digitalização, que costumam analisá-la como avanço tecnológico ou forma de precarização do trabalho, em perspectivas funcionalistas ou críticas, respectivamente. Assim, analisamos a digitalização como forma de organizar a expropriação de dados dos usuários para garantir os resultados financeiros e poder para as organizações.

Contribuições teóricas e práticas: A principal contribuição teórica desse trabalho repousa sobre o avanço da teoria do dark side das organizações e sua relação com o conceito de capitalismo de vigilância e o papel do Estado no mundo digitalizado. Sobre as contribuições práticas, acreditamos que, em uma sociedade digitalizada, a atenção à operacionalização das organizações plataformizadas é emergencial, assim como a cobrança da atuação do Estado como ator principal na regulação das relações entre plataformas e usuários.

Palavras-chave: Dark side da digitalização, Lei Geral de Proteção de Dados, Termos de Consentimento, Capitalismo de Vigilância, Uber.

\section{Abstract:}

Research Objective: We analyzed the types of misconduct that make up the terms of consent of a digitized organization, in the era of surveillance capitalism, and the conduct of the State concerning such practices. 
Theoretical framework: The article is developed from a critical perspective supported by organizations' dark side theories and surveillance capitalism. Such an option is justified by the cause-and-effect relationship between so-called surveillance capitalism and practices characterized as misconduct by organizations' dark-side theory.

Methodology: The document analysis method was adopted, through which we analyzed the content of Uber's consent terms and Laws No. 12,965 of 2014 ("Marco Civil da Internet") and No. 13,709 of 2018 ("General Protection of Data Law").

Results: It was found that Uber's consent terms conflict with the laws in more than seventy points and obscure data expropriation practices, characterizing the organization's misconduct. The legislation created to protect the user and his data is systematically extended, protecting organizations from surveillance capitalism and leaving users vulnerable.

Originality: The article expands the studies on digitalization, which usually analyze it as a technological advance or a form of precarious work, in functionalist or critical perspectives, respectively. Thus, we analyze digitalization to organize user data expropriation to guarantee financial results and power for organizations.

Theoretical and practical contributions: The main theoretical contribution of this work rests on the advancement of dark side of organizations theory and its relationship with the concept of surveillance capitalism and the role of the State in the digitalized world. Regarding practical contributions, we believe that in a digitalized society, attention to the operationalization of platform organizations is an emergency, as is the demand for the State to act as the main actor in the regulation of relations between platforms and users.

KEYWORDS: Dark side of digitization, General Data Protection Law, Consent Terms, Surveillance Capitalism, Uber.

\section{Resumen:}

Objetivo de la investigación: Analizamos los tipos de mala conducta que componen los términos de consentimiento de una organización digitalizada, en la era del capitalismo de vigilancia, y la conducta del Estado en relación a tales prácticas.

Marco teórico: El artículo se desarrolla desde una perspectiva crítica sustentada en las teorías del lado dark de las organizaciones y el capitalismo de vigilancia. Tal opción está justificada por la relación de causa y efecto entre el llamado capitalismo de vigilancia y las practicas caracterizadas como mala conducta por la teoría del lado oscuro de las organizaciones.

Metodología: Se adoptó el método de análisis de documentos, mediante el cual se analizó el contenido de los términos y leyes de consentimiento de Uber No. 12,965 de 2014 ("Marco Civil da Internet") y No. 13,709 de 2018 (Ley General de Protección) de dados).

Resultados: Se encontró que los términos de consentimiento de Uber entran en conflicto con las leyes en más de setenta puntos y oscurecen las prácticas de expropiación de datos, que caracterizan la mala conducta de la organización. La legislación creada para proteger al usuario y sus datos se amplía sistemáticamente, protegiendo a las organizaciones del capitalismo de vigilancia y dejando a los usuarios vulnerables.

Originalidad: El artículo amplía los estudios sobre digitalización, que suelen analizarla como un avance tecnológico o una forma de trabajo precario, en perspectivas funcionalistas o críticas, respectivamente. Así, analizamos la digitalización como una forma de organizar la expropiación de los datos de los usuarios, para garantizar resultados económicos y poder para las organizaciones.

Aportes teóricos y prácticos: El principal aporte teórico de este trabajo se basa en el avance de la teoría del lado oscuro de las organizaciones y su relación con el concepto de capitalismo de vigilancia y el papel del Estado en el mundo digitalizado. En cuanto a los aportes prácticos, creemos que en una sociedad digitalizada, la atención a la operacionalización de las organizaciones de plataformas es una emergencia, así como la demanda del Estado para actuar como actor principal en la regulación de las relaciones entre plataformas y usuarios.

Palabras clave: Lado oscuro de la digitalización, Ley General de Protección de Datos, Condiciones de Consentimiento, Capitalismo de Vigilancia, Uber.

\section{INTRODUÇÃO}

No ano de 2019 o Fórum Econômico Mundial classificou os dados como o novo petróleo da economia mundial, tendo em vista que se trata de uma riqueza que resulta em importantes resultados para as indústrias da atualidade (World Economic Forum [WEF], 2019). Ao classificar os dados como uma riqueza que interessa às indústrias, o Fórum Econômico Mundial definiu que este seria o foco dos esforços, transparentes e obscuros, do mundo capitalista pelos próximos anos. Desta forma, observa-se uma tendência relacionada à captação desta riqueza por um grupo de organizações que têm a web como seu ecossistema por meio da relação que estabelecem com cidadãos, clientes e usuários, direta e indiretamente (O’Neil, 2016; Zuboff, 2019). 
A percepção dos dados como uma possível fonte de riqueza origina-se na era da web 2.0 (O’Reilly, 2009), em que as interações entre os indivíduos, entre os indivíduos e as organizações e, ainda, entre as organizações, passam a ser quantificadas e dataficadas, resultando em métricas de comportamento (Couldry, 2017; Couldry \& Mejias, 2019; Zuboff, 2019). Com isso, os sentimentos, as expressões (verbais, faciais, entre outras), as opiniões e as percepções, voluntárias ou não, e nomeadas como excedentes de comportamento (Zuboff, 2019), tornam-se passíveis de serem mercantilizados e negociados como produtos (O’Neil, 2019; Srniceck, 2019).

A negociação e mercantilização de dados faz parte do rol de atividades das organizações que compõem o chamado capitalismo de vigilância (Zuboff, 2019), caracterizadas por reivindicarem "unilateralmente a experiência humana como matéria-prima gratuita para tradução em dados comportamentais . . que antecipam o que você fará agora, em breve, e depois" para, posteriormente, "negociarem esses produtos de previsão em um novo tipo de mercado para previsões comportamentais que eu chamo de mercados futuros comportamentais." (Zuboff, 2019, p. 32). A operacionalização do capitalismo de vigilância ocorre, em larga medida, por meio das plataformas digitais e de suas interfaces, que controlam e direcionam as decisões dos usuários (Shah, 2019).

Diante deste cenário, o presente trabalho tem como objetivo analisar, a partir de uma lente crítica, as práticas destas organizações e, em especial, a forma como elas conduzem a captação dos dados de seus usuários por meio de práticas que podem ser consideradas desvios das organizações, caracterizando um dark side (Vaughan, 1999; Lisntead, Maréchal, \& Griffin, 2014). Para apontar as práticas das organizações digitais como obscuras, esta investigação levantou o papel do Estado por meio das leis que devem colocar freios nas práticas do capitalismo de vigilância no Brasil, já que, em larga medida, a tecnologia por si só já possui um status de legitimidade em uma sociedade tecnocrática (Feemberg, 2017).

O objeto de análise é a organização Uber, em especial seus termos de consentimento, devido ao fato de essa organização ser foco de pesquisas anteriores sobre a precarização do trabalho, mas não sobre o capitalismo de vigilância. A empresa Uber é classificada como uma empresa de compartilhamento de viagens (ride sharing), considerada uma inovação disruptiva frente às tradicionais empresas de táxi (Cramer \& Krueger, 2016; Skok \& Baker, 2019). A Uber tornou-se uma empresa com múltiplas divisões de negócio, como o próprio transporte de passageiros e a entrega de alimentos, utilizando como mão de obra indivíduos sem vínculo empregatício formal com a empresa, mas contratados via plataforma (Cornelissen \& Cholakova, 2019; Andressen, Lervik-Olsen, Snyder, Van Riel, SweeneyVan, \& Vaerenbergh, 2018). Além disso, os clientes contratam o serviço por meio de um aplicativo instalado nos smartphones, em que é possível acompanhar o motorista, verificar seus dados, pagar e avaliar o serviço (Mittendorf, 2017).

A escolha apresentou-se adequada, já que as organizações digitais que compõem o capitalismo de vigilância mimetizam as práticas relacionadas à captação de dados dos usuários (Venturini, Louzada, Maciel, Zingales, Stylaniou, \& Belli, 2016). Com isso, as práticas adotadas por uma organização podem apresentar semelhanças com as práticas adotadas por outras organizações que compartilham este ecossistema digital e plataformizado (Srniceck, 2017, Vianna \& Meneghetti, 2020).

Por meio de uma pesquisa documental entre os meses de janeiro e março do ano de 2021, foram efetuadas as coletas e análises de conteúdo dos termos de consentimento da Uber (Termo de Uso, Políticas de Privacidade e Políticas de Cookies) e seus dispositivos foram confrontados com cada um dos artigos da Lei 12.965 de 2014, comumente chamada de "Marco Civil da Internet", e da Lei 13.709 de 2018, a comumente chamada de Lei Geral de Proteção de Dados (LGPD). Esta última, criada especificamente para regulamentar a política de captação, transação e armazenamento de dados, teve sua vigência confirmada desde o mês de agosto de 2020, após ser postergada duas vezes desde 2018 , sob as mais variadas justificativas.

Faz-se necessário frisar que a presente investigação só foi possível devido ao seu caráter multidisciplinar, haja vista que, para analisar o comportamento da organização objeto deste estudo, foi preciso conjugar a lente organizacional à lente do Direito, já que as práticas organizacionais envolvem posse, transações, políticas de 
armazenagem, entre outros aspectos relacionados à captação de dados pessoais. Além disso, tais práticas são reguladas por contratos digitais acordados entre as organizações e os indivíduos ou outras organizações.

O presente trabalho está organizado da seguinte forma: na sequência desta introdução é exposto o referencial teórico para, em seguida, apresentarmos o método de pesquisa e os resultados das análises. Os resultados da pesquisa servem como base para a discussão do tema sob a orientação das perguntas de pesquisa e, por fim, é apresentada a conclusão da pesquisa.

\section{O Dark Side da Digitalização}

A descrição das organizações dentro de um sistema capitalista como instituições que buscam objetivos positivos para a sociedade e passivas em relação àquilo que se apresenta nos ambientes em que se encontram não é mais adequada (Perrow, 1991; Alcadipani \& De Oliveira Medeiros, 2019). Isso ocorre desde que as organizações passaram a dominar as relações com seus stakeholders e buscar a legitimação de seus resultados financeiros e poder por meio da racionalidade instrumental de leis, técnicas e regulamentos (Perrow, 1991). Com isso, estudos que investigam as maneiras como tais organizações se estruturam para, por um lado, produzir um ambiente permeado por injustiça social e instabilidade econômica e social e, por outro lado, garantir a preocupação técnica dos indivíduos e afastar a reflexão crítica, passaram a ter relevância (Adler, Forbes, \& Willmott, 2007; Kuenzer, 2002).

A crítica ao sistema capitalista, historicamente, apresenta-se como um desafio, tendo em vista que as organizações que dominam este sistema, quando confrontadas por questionamentos sobre suas condutas, utilizam os próprios questionamentos como subterfúgio para sua legitimação (Boltanski \& Chiapello, 2009). Entre os exemplos deste fenômeno estão o golpe militar de 1964 no Brasil, orquestrado pelos Estados Unidos com o objetivo de garantir a pilhagem dos pobres pelos ricos e justificado pela falácia da ameaça comunista (Chomsky, 2002) e a criação de leis no Brasil que legitimam a precarização do trabalho e da vida do trabalhador, a partir da crítica ao desemprego (Antunes, 2018). Em resumo, sempre que uma esfera do capital é atingida por uma crítica, tal crítica é utilizada como justificativa para novas investidas do capital sobre os mais variados direitos dos cidadãos.

Este exercício do capital de encortinar o lado obscuro das práticas organizacionais por meio de discursos de benevolência é renovado a cada novo momento histórico e já foi explorado anteriormente. O chamado dark side das organizações é apresentado como o resultado de práticas organizacionais internas, em processos e atividades rotineiros que objetivam atender à demanda das organizações por maior previsibilidade em seu ambiente e distanciamento de resultados negativos (Vaughan, 1999; Linstead, Maréchal, \& Griffin, 2014). Este lado obscuro é abordado nos estudos organizacionais sob perspectivas como mau comportamento dos funcionários como resposta a um sistema exploratório (Medeiros \& Alcadipani, 2016), o dark side das privatizações das organizações (Silva \& Abdalla, 2020) e dos crimes corporativos de repercussão ambiental, social e humana (Da Costa Lage \& Medeiros, 2019).

Em seu trabalho seminal, Vaughan (1999) categoriza os tipos de desvios das organizações de três formas: os erros são caracterizados como atos ou omissões que geram resultados inadequados e inesperados; a má conduta envolve atos ou omissões que quebram ou rompem com as regras, leis ou regulamentos, com o objetivo de se obterem resultados para a organização; e o desastre é compreendido como um acidente de grande repercussão e de impactos sociais negativos, usualmente precedido de uma má conduta ou de um erro.

Tendo em vista as renovações do capitalismo diante de crises e movimentos estruturais impostos à sociedade em geral como forma de sobrevivência do sistema, as práticas que caracterizam o dark side atingem atualmente as relações sociais mediadas por novos dispositivos tecnológicos conectados (Adler, 1992; Langley \& Leyshon, 2017). O advento da internet não gerou apenas uma maximização da taxa de exploração dos indivíduos, mas também novos modelos organizacionais que permitem a mercantilização de todo o usuário e de todos os usuários (Fuchs, 2017). Sendo assim, a importância de estudos que analisem a 
relação entre organizações e novas tecnologias digitais se dá pelo papel desempenhado por estes dois fatores na sociedade, tendo em vista que o objetivo da tecnologia que costumava ser orientado por seus usuários passou a ser amplamente definido pelas organizações (Bijker, 1997; Michels \& Steyaert, 2019; Flemming, 2019).

Para além das simples organizações que intermediam a comunicação entre duas partes, como sugerido por Feenberg (2017), as organizações digitais oriundas da chamada web 2.0 (O’Reilly, 2009) focaram seus esforços na conquista do poder por meio do "colonialismo de dados" (Morozov, 2017; Couldry \& Mejias, 2019). Esta prática, também nomeada como capitalismo de vigilância (Zuboff, 2019), capitalismo de plataforma (Srniceck, 2017) e vigilância da web 2.0 (Fuchs, 2011), gera receitas para um reduzidíssimo número de indivíduos e suas organizações, a partir do controle da vida dos indivíduos por meio de uma expropriação massiva de dados e quantificação (ou dataficação) dos comportamentos, emoções e percepções das pessoas (O’Neil, 2016; Taplin, 2017; Couldry \& Mejías, 2019; Zuboff, 2019). Esse fenômeno pode ocorrer tanto por meio do controle dos clientes e usuários das plataformas quanto pelo controle dos próprios funcionários, como em seus trajetos ou hábitos (Elmholdt \& Elmholdt, \& Haar, 2021; Wood, Graham, Lehdonvirta, \& Hjorth, 2019)

Os estudos referidos acima são uma alternativa recente às abordagens que observam organizações digitais como Facebook, Google e Uber por uma perspectiva funcionalista da digitalização em termos de eficiência, do Big Data e da Internet das Coisas, usualmente concentrados em áreas como Sistemas de Informação, Operações e Marketing (Feemberg, 2012; Yoo, Boland, Lyytinen, \& Majchrzak, 2012; Constatinou \& Kallinikos, 2015).

A abordagem crítica de gestão vem sendo utilizada como lente para estudos que questionam questões da digitalização, como novas formas de trabalho (Fuchs, 2017); precarização do trabalho, sequestro da subjetividade e exploração dos trabalhadores da Uber (Da Silva \& Nascimento, 2018; Francos \& Ferraz, 2019); expropriação de dados e capitalismo de vigilância (Vianna \& Meneghetti, 2020); e definição de políticas de direitos autorais (Whelan, 2019). Essas pesquisas exploram o lado obscuro da digitalização, que foi foco, recentemente, de uma chamada do periódico Organization (Trittin, Scherer, Whelan, \& Munro, 2019).

Diante destas categorias, emerge o questionamento a respeito dos tipos de desvios que são cometidos pelas organizações da era do capitalismo de vigilância (Zuboff, 2019).

\section{CAPitAlismo DE VigilâNCIA}

O termo capitalismo de vigilância começou a ser explorado no Brasil a partir das leituras do texto seminal da Professora de Harvard, Soshana Zuboff (Zuboff, 2019). O termo já havia aparecido anteriormente em uma análise que envolvia a transformação econômica dos Estados Unidos, que passou dos gastos militares para o gasto em consumo e marketing, até a acumulação de capital pelo monopólio digital (Foster \& McChesney, 2014). No entanto, foi Zuboff quem trouxe uma perspectiva mais próxima da análise do capitalismo de vigilância sob a lente das organizações (Zuboff, 2015; 2019).

Em seu livro de 2019, Zuboff aborda a forma como o capitalismo de vigilância se tornou o modelo dominante econômico a partir da expropriação de dados dos indivíduos, por meio da digitalização de quase toda a vida humana (Zuboff, 2019). O termo ainda aparece em outros trabalhos com diferentes derivações que utilizam termos como captura, capitalismo de plataforma, vigilância da web 2.0, sistemas de vigilância e dataficação, mas sempre seguindo na direção do domínio e poder a partir dos dados (Fuchs, 2010; Foster \& McChesney, 2014; Srnicek, 2017; Charitsis, Zwick, \& Bradshaw, 2018; Couldry \& Mejias, 2019).

Para capturar essa importante matéria-prima do capitalismo de vigilância, as organizações desenvolveram uma nova forma de mediação das relações sociais entre indivíduos, entre indivíduos e organizações e entre as próprias organizações, a plataformização (Van Dijck, 2013). Este modelo de negócio que tomou conta da vida dos indivíduos é viabilizado por uma poderosa conectividade, aliada a softwares que viabilizam e 
cooptam as ações entre todos estes atores, a web 2.0 (Van Dijck, 2013, Fuchs, 2017). A capacidade de conexão aliada a uma visão de geração de valor a partir da acumulação de dados tornou as organizações, ao mesmo tempo, prestadoras de serviços e expropriadoras de dados (Van Dijck, 2013; Zuboff, 2019). Atualmente, a expropriação de dados traveste-se de empoderamento do usuário e certezas artificiais (O’Neil, 2016; Zuboff, 2019).

A expropriação e acúmulo de dados são fundamentais para as organizações que dominam a era do capitalismo de vigilância transformarem tais dados em resultados financeiros, antes de seus concorrentes (Srnicek, 2017). Apenas a partir dos dados, as organizações conseguem manter suas hegemonias e o controle dos indivíduos e de suas emoções em um mundo totalmente digitalizado (Bond et al., 2012; Kramer, Guillory, \& Hancock, 2014; Zuboff, 2019). Estudos na área de comportamento humano mostram que as redes sociais são capazes de alterar comportamentos, afetar as emoções e influenciar decisões (Bond et al., 2012; Kramer, Guillory, \& Hancock, 2014).

Estas organizações, denominadas redes sociais, websites, aplicativos, entre outros nomes, são estruturadas ou mediadas por plataformas digitais, que são espaços onde os indivíduos podem estar ao mesmo tempo em que softwares e algoritmos são executados para os mais variados objetivos (Pasquale, 2015; Srnicek, 2017; Langley \& Leyshon, 2017; Woodcock \& Graham, 2019). Essas plataformas digitais apresentam interfaces convidativas e agradáveis e usualmente estão relacionadas com a produção de um bem, a prestação de um serviço presencial ou on-line, cooperação entre usuários e empoderamento dos indivíduos (Srnicek, 2017; Shah, 2019). No entanto, o objetivo dessas plataformas digitais na sociedade capitalista pode ser resumido à captação de dados provenientes de nossas atividades sociais, emocionais e físicas para sua mercantilização (O’Neil, 2016; Fuchs, 2017; Zuboff, 2019; Vianna \& Meneghetti, 2020).

A mercantilização dos dados a partir da relação entre usuários e plataformas digitais ocorre de diferentes formas, entre elas categorização de potenciais compradores para um produto ou serviço, mapeamento de expressões faciais e verbais, análise de comportamento e publicidade comportamental, entre outras (O’Neil, 2016; Srnicek, 2017; Zuboff, 2019). Com isso, as organizações que mediam sua relação com consumidores por meio de plataformas digitais podem não apenas desenvolver produtos e serviços customizados, mas especialmente direcionar o comportamento dos usuários para a aquisição daquilo que as organizações vendem (O’Neil, 2016; Srnicek, 2017; Zuboff, 2019; Vianna \& Meneghetti, 2020). Este direcionamento é possível devido às regras definidas pelas próprias organizações por meio de termos de consentimento que as autorizam a cruzar dados oriundos de diferentes plataformas e aplicativos parceiros para garantir o interesse do usuário naquilo que desejam (Srnicek, 2017).

Para que a expropriação de dados ocorra dentro de uma certa normalidade, dois fatores são importantes: algoritmos e consentimento do usuário (Pasquale, 2015; Srnicek, 2017; Zuboff, 2019) Quanto aos algoritmos, as explicações usualmente são vazias sobre seu funcionamento, tendo em vista que as organizações se aproveitam da própria crítica em relação à privacidade de seus usuários para privar a todos de informações sobre seu funcionamento (Pasquale, 2015). Aparentemente, apesar do fato de existirem leis formuladas com o intuito de proteger os dados que são processados nestes algoritmos, as mesmas leis acabam protegendo as organizações de evidenciarem como os dados são explorados (Pasquale, 2015). Quanto aos termos de consentimento, explicaremos a seguir suas características.

\section{Consentimentos e a proteção do usuário}

O registro em plataformas digitais está usualmente pautado na concordância com termos de serviços, políticas de privacidade e outros documentos que são criados pelas próprias plataformas, os termos de consentimento (Venturini et al., 2016). A presença quase automática da frase "Eu li e aceito os termos de serviço" nas plataformas digitais é acompanhada do chamado consentimento nas formas "aceita tudo ou não usa nada" ou "pegue ou largue" (Venturini et al., 2016; Zuboff, 2019). Este tipo de consentimento afasta qualquer 
possibilidade de escolha por parte do usuário e naturaliza seu consentimento sem conhecimento (Obar \& Oeldorf-Hirsch, 2018). Por outro lado, para que o consentimento tivesse sentido para ambas as partes, organização digital e usuário, estes últimos deveriam ser municiados com todas as informações sobre o funcionamento das plataformas (Zarsky, 2019).

Os consentimentos são documentos definidos por somente uma das partes, a organização, e direcionados a qualquer usuário, sem qualquer distinção, e abarcam diversos documentos como políticas de privacidade, políticas de cookies, dentre outros (Venturini et al., 2016). Em estudo desenvolvido no ano de 2016, pesquisadores brasileiros verificaram que a escassez de informações nos documentos alcançados pelo consentimento do usuário não é uma exceção, mas sim o seu modus operandi (Venturini et al., 2016). Contudo, mesmo com essa escassez de informações a respeito do tratamento dos dados, mais de $90 \%$ dos usuários não leem esses documentos adequadamente (Obar \& Oeldorf-Hirsch, 2018).

A efemeridade da concordância dos usuários sobre as práticas das plataformas digitais deve-se ao desconhecimento dos titulares dos dados pessoais sobre o fluxo de seus dados, dentro e fora dessas plataformas, em uma medida que o chamado consentimento significativo (meaningful consent) perdeu seu sentido (Zarsky, 2019). Nessa perspectiva, dentre os princípios que validam o tratamento de dados pessoais, encontra-se o Princípio da Finalidade (purpose limitation), cujo conteúdo determina que a coleta desses dados deve prever uma finalidade específica e restringir-se a ela (Forgó, Hanold, \& Schutze, 2017). Sendo assim, os dados não devem ser utilizados para outros propósitos, mesmo que compatíveis com a finalidade do consentimento inicial (Ghani, Hamid, \& Udzir, 2016).

As garantias relacionadas aos termos de consentimento, com o objetivo de proteger os usuários e cidadãos, usualmente estão relacionadas às leis específicas de cada país (Zuboff, 2019). Desta forma, assim como a União Europeia definiu sua lei específica para a proteção dos dados e de seus cidadãos, o Regulamento Geral de Proteção de Dados da União Européia, o GDPR (Voigt \& Von Dem Bussche, 2017), em 2018 foi promulgada no Brasil a Lei 13.709, chamada Lei Geral de Proteção de dados. Trata-se de uma Lei Ordinária, promulgada em 14 de agosto de 2018, a Lei Ordinária n. 13.709/2018, denominada Lei Geral de Proteção de Dados Pessoais Brasileira (LGPD), que estabelece normas gerais mínimas a respeito da proteção de dados pessoais, com a finalidade de proteger direitos como privacidade, liberdade de expressão e de informação, da intimidade, honra e imagem, defesa do consumidor, bem como os direitos humanos e o livre desenvolvimento da personalidade e dignidade, dentre outros (Lei n. 13.709, 2018).

É importante mencionar, ainda, que a LGPD sofreu, desde sua promulgação, dois adiamentos de sua vigência, sendo o primeiro decorrente da Lei 13.853 de 2019, que passou a vigência de janeiro do ano de 2020 para agosto do ano de 2020 (Lei n. 13.853, 2019). Em seguida, no mês de maio de 2020, a Medida Provisória 959/2020 adiou a vigência da LGPD para o mês de maio do ano de 2020 (Medida Provisória n. 959, 2020). O primeiro adiamento foi justificado pela dificuldade de as organizações se adequarem às exigências da LGPD e o segundo adiamento se deu pela mesma justificativa, mas agravado pela pandemia da COVID-19 (Cury, 2020). Ainda sobre o adiamento da LGPD, desde janeiro de 2020 tramita uma proposta do Projeto de Lei 5.762 (Projeto de Lei n. 5.762, 2019) para postergar o vigor da lei para o ano de 2022. Em resumo, desde sua promulgação, a LGPD sofreu dois adiamentos e ainda tramita uma proposta para um terceiro adiamento.

Além da LGPD, a Lei 12.965, de 23 abril de 2014, popularmente conhecida como "Marco Civil da Internet", contém artigos referentes aos direitos e garantias dos usuários de internet. A referida lei foi criada com o objetivo de "estabelecer princípios, garantias, direitos e deveres para o uso da Internet no Brasil" (Lei n. 13.079, 2018) e "tutelar os direitos da personalidade nas redes sociais virtuais (De Teffé \& De Moraes, 2017, p. 108). Apesar de não ser uma lei formulada especificamente para regular a relação entre plataformas digitais e usuários, apresenta artigos que garantem alguma privacidade ao usuário (De Teffé \& De Moraes, 2017, p. 108). Mesmo assim, é possível afirmar que a complexidade das redes digitais e as formatações globais dessas organizações faz com que as relações entre usuários e plataformas digitais ou redes sociais estejam de um ambiente inadequadamente regulado (Tomasevicius, 2016). 
Diante do apresentado até aqui, observa-se que as organizações que mediam sua relação com os cidadãos por meio de plataformas digitais teriam seus limites estabelecidos por termos de consentimento, que são desenvolvidos em acordo com a legislação vigente. Com isso, emerge o questionamento sobre o papel do Estado e das leis nesta atividade de expropriação que vivemos no capitalismo de vigilância.

\section{Metodologia}

Esta pesquisa tem um caráter exploratório, devido ao ineditismo de pesquisas que investigam a forma como as organizações digitais se apossam dos dados de seus usuários e os exploram por meio de políticas e termos obscuros. Sendo assim, diante do referencial teórico desenvolvido e das lacunas de pesquisa que se apresentaram, buscamos responder às seguintes perguntas: Quais os tipos de desvios cometidos por uma organização da era do capitalismo de vigilância? Qual papel do Estado e das leis nesta atividade de expropriação que vivemos no capitalismo de vigilância?

A escolha da organização Uber deu-se, incialmente, por uma inquietação dos próprios pesquisadores quanto às formas com que seus dados e os dados relacionados a seus comportamentos junto à plataforma eram processados pela organização. A partir desta inquietação, pesquisas iniciais foram efetuadas com leitura dos termos de consentimento da Uber. Além disso, a plataforma Uber é, constantemente, objeto de pesquisas relacionadas às condições de trabalho, mas se apresenta, ainda, como um importante objeto de estudos relacionados ao seu processo de digitalização, haja vista que são muitas e diversas as fontes de dados captados pela plataforma: usuários (passageiros), motoristas, entregadores (Uber Eats), estabelecimentos de comércio de alimentos e clientes de comércios de alimentos. Além disso, a Uber ainda caracteriza-se por captar dados de localização, mensagens e conversas entre passageiros e motoristas. Esta última fonte já está em funcionamento em diversas capitais do Brasil e é apresentada pela empresa como uma forma de aumentar a segurança e compreender o comportamento que origina avaliações negativas de motoristas (Uber, 2020).

Para responder às perguntas de pesquisa, optamos pelo delineamento de pesquisa qualitativa, desenvolvido a partir do método de pesquisa documental, que permite o acesso a informações a respeito do objeto de pesquisa que poderiam ser dificultados pelo próprio objetivo e o entendimento de um determinado objeto de pesquisa dentro de seu contexto histórico e sociocultural (Godoy, 1995; Sá-Silva, Almeida, \& Guindani, 2009). O delineamento qualitativo utilizado neste estudo se apoia em uma construção interpretativista e indutiva, que permite ao pesquisador buscar os dados da pesquisa, neste caso, a partir do exame de documentos que balizam a relação entre os indivíduos e uma determinada organização (Creswel \& Creswel, 2017). Para a escolha, exploração, tratamento, inferências e interpretação dos documentos selecionados, optamos pela abordagem de Bardin (2011).

\section{Coleta de DAdos}

A coleta de dados nesta pesquisa ocorreu em três etapas distintas, entre os meses de janeiro e março do ano de 2020. A primeira etapa foi a pré-análise (Bardin, 2011), em que os autores definiram os documentos que seriam levantados e a partir de quais objetivos cada documento seria analisado. Tendo em vista que a pesquisa em websites e plataformas digitais não é usual, houve o cuidado de não ampliar o número de documentos para além da necessidade do trabalho. Definiu-se nessa etapa que os documentos coletados e posteriormente analisados seriam os documentos legais que delineiam a proteção de dados dos usuários de aplicativos e os documentos da organização que orientam a captação, processamento e transferência dos dados de usuários e terceiros. Para a coleta dos documentos legais, foram acessados os websites do governo federal em que se encontram as leis concernentes à proteção dos dados dos usuários de plataformas digitais no Brasil: A Lei 
13.709 de 2018, conhecida como Lei Geral de Proteção de Dados, e a Lei 12.965, de 23 abril de 2014, nomeada como Marco Civil da Internet.

Concomitantemente, os pesquisadores coletaram no website da Uber e no aplicativo da empresa, os seguintes documentos: Termos de Serviço, a Política de Privacidade e a Política de Cookies. Os documentos são públicos e aqueles documentos que não possuíam a opção de download foram copiados integralmente para a posterior análise.

Análise dos dados

A abordagem indutiva ocorreu por meio da organização, análise sistemática e codificação dos dados dos documentos coletados (Bardin, 2011; Charmaz, 2006). O processo foi executado separadamente por dois pesquisadores, com o objetivo de atribuir maior robustez ao resultado. Para a definição das categorias de análise, cada pesquisador percorreu o seguinte percurso. Primeiro foram verificados os artigos e incisos do Marco Civil da Internet e, em seguida, os artigos e incisos da LGPD. Nesse momento, foram levantados os artigos e incisos que fazem referência, diretamente, à proteção dos dados pessoais de usuários e terceiros. Para isso, foram excluídos os artigos e incisos que abordavam, por exemplo, a transferência internacional de dados, a fiscalização e as sanções administrativas, artigos referentes à composição da Autoridade Nacional de Proteção de Dados (ANPD) e do Conselho Nacional de Proteção de Dados (CNPD).

A segunda etapa foi a análise de cada um dos documentos da empresa Uber: Termo de Serviço, a Política de Privacidade, e a Política de Cookies. Os pesquisadores analisaram linha a linha cada um dos documentos, identificando artigos que se referem a possíveis capturas, armazenamento ou compartilhamento dos dados de usuários e que poderiam conflitar com alguma das legislações. Essas duas etapas foram executadas por dois pesquisadores autores do artigo, com o auxílio do software Microsoft Excel para planilhar e organizar possíveis pontos de conflito entre os documentos da organização e as legislaçóes.

Com os resultados em mãos, os três pesquisadores passaram para a codificação dos conflitos encontrados. Para cada conflito entre a legislação e os documentos da organização, os pesquisadores observaram que as ocorrências eram codificadas dentro de três principais categorias, que tratavam da ausência de necessidade de consentimento por parte do usuário quanto a uma eventual alteração das políticas; da possibilidade de a organização compartilhar os dados coletados com terceiros, sem informar especificamente quem seriam esses terceiros e quais os dados compartilhados; e do processamento e manipulação dos dados dos usuários sem especificar períodos pelos quais os dados seriam tratados pela organização e as etapas de processamento dos dados. Dessa forma, foram definidas três categorias não exaustivas: consentimento dissolvido, compartilhamento irrestrito e expropriação de dados. Em seguida são apresentados os resultados da pesquisa.

\section{ApresentaÇÃo dos Resultados}

\section{Pontos de conflito entre a LGPD e os documentos da Uber}

No Quadro 2 apresentamos os pontos de conflito entre os dispositivos dos termos de consentimento da Uber e os artigos da LGPD. Optamos por esta forma de apresentação devido à grande quantidade de incompatibilidades encontradas, em nossa análise, entre os documentos, nesta etapa da pesquisa. Ao todo, foram mais de setenta ocorrências de incompatibilidade entre os documentos da Uber e a LGPD. Essas ocorrências foram computadas da seguinte forma:

a) Dentro dos documentos da organização, que são apresentados na Coluna 1 (política de privacidade, termos e condições e declaração de cookies), um determinado item do documento confronta a legislação;

b) Esse item que confronta a legislação é apresentado na Coluna 2 (Visão geral; Coleta e uso de dados; Opções e transparência; Alterações deste aviso; Do relacionamento contratual; Do conteúdo fornecido pelo 
usuário; Legal e declaração de cookies; visão geral para tecnologias e afins; Sincronização e relevância de anúncios - Suas opções; Tipos e finalidades dos cookies);

c) Para identificar qual o artigo, parágrafo e (ou) inciso da Lei que é confrontado pelo documento da organização, descrevemos nas Colunas 3 (Marco Civil da Internet) e 4 (LGPD) o artigo, o inciso e o parágrafo.

Em resumo, a linha 2 do Quadro 1 está relacionada ao documento "Política de Privacidade" (Coluna 1), e o item "Visão geral" desse documento (Coluna 2), conflitando com o "Art. 7º, incisos VIII e IX" do Marco Civil da Internet (Coluna 3) e "Art. 2, inciso III; Art. 6, inciso I" da LGPD (Coluna 4). Isso significa que o item Visão Geral da Política de privacidade da Uber apresenta três ocorrências de incompatibilidade, sendo uma com um artigo do Marco Civil da Internet e duas com dois artigos da LGPD.

Quadro 1 - Pontos de conflito entre os dispositivos dos termos de consentimento da Uber e os artigos da LGPD.

\begin{tabular}{|c|c|c|c|}
\hline Documento & $\begin{array}{l}\begin{array}{l}\text { Item do termo que conflita com a LGPD e com o Marco Civil } \\
\text { da Internet }\end{array} \\
\end{array}$ & Artigos do Marco Civil da Intermet desrespeitados & Artigos da LGPD desrespeitados \\
\hline \multirow{3}{*}{ Politica de privacidade } & & $\begin{array}{l}\text { Art. } 7^{\circ} \text {, incisos VIII } \mathrm{eIX} \\
\text { Art }\end{array}$ & 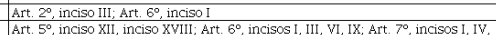 \\
\hline & Coleta e uso de dados & & 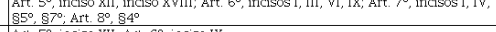 \\
\hline & 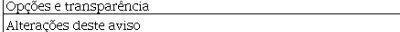 & 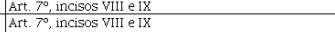 & $\begin{array}{l}\text { Art. } 5^{\circ} \text {, inciso XII Art. } 6^{\circ} \text {, inciso IX } \\
\text { Art. } 7^{\circ} \text {, inciso I, } 85^{\circ}, 87^{\circ} \text {. Art. } 8^{\circ}, 83^{\circ}, 84^{\circ} \cdot \text { Art. } 9^{\circ}, 81^{\circ}, 8^{2}\end{array}$ \\
\hline \multirow{3}{*}{ Termos e condiç̄os } & Do relacionamento contratual & Afrt 70, incisos VII, YIII e IX & Afrt. 5 , inciso XII \\
\hline & 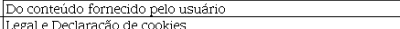 & 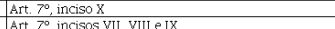 & Art. $7^{\circ}, 85^{\circ}, 87^{\circ} ;$ Art $8^{\circ}, 84^{\circ}, 85^{\circ} ;$ Art $99^{\circ}, 81^{1}, 82^{\circ}$, \\
\hline & 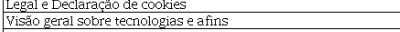 & Art $7^{\circ}$, incisos VIII eIX & $\begin{array}{l}\text { Ant. } 6^{\circ} \text {, incisos I, III, V] } \\
\text { Art. } 2^{\circ} \text {, inciso I; Art. } 6^{\circ} \text {, incisos I, III, VI }\end{array}$ \\
\hline \multirow[t]{2}{*}{ Declaraçāo de cookies } & Sincronizaçāoa e relevância de anüncios - Suas opp̣ōes & Art. 70, inciso YII & Art. $6^{\circ}$, incisos L, III, V]; Ast. $8^{\circ}, 83^{\circ}, 84^{\circ}$ \\
\hline & Tipos e finalidades dos cookies & Art. $7^{\circ}$, incisos VII, VIII e IX & 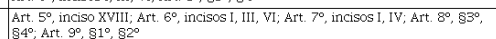 \\
\hline
\end{tabular}

Fonte: Os autores com base nos dados da pesquisa.

\section{Categorias analíticas}

Em seguida, são apresentadas as categorias analíticas que emergiram das análises dos documentos e são expostos exemplos dos conflitos entre os termos de consentimento e as leis que compóem o corpus deste artigo, o Marco Civil da Internet e a LGPD. As categorias consentimento dissolvido, compartilhamento irrestrito e expropriação de dados não são exaustivas e auxiliaram a pesquisa no que tange à compreensão das formas como uma organização digital utiliza tais documentos como instrumentos de legitimação da expropriação dos dados pessoais de seus usuários. Além disso, não são abordadas todas as mais de setenta passagens em que os termos de consentimento conflitam com a legislação, mas utilizamos aquelas mais relevantes para apresentar a construção da categoria.

Para melhor esclarecer ao leitor a relação entre as categorias e os elementos que as compõem, primeiro explicamos o significado do termo utilizado na categoria, tanto por meio de uma definição leiga, proveniente de dicionário, quanto por meio de uma definição técnica, proveniente de Lei ou publicação da área jurídica. Em seguida elencamos os exemplos extraídos das comparações entre os Termos de Consentimento, o Marco Civil da Internet e a LGPD.

\section{Consentimento dissolvido}

Segundo o dicionário Aurélio, o termo "consentimento" significa licença, dar permissão, concordância entre partes e é relacionado, ainda, a outros termos que ensejam que um indivíduo concorda com algo ou com uma ação de outra parte em relação a ele (Aurélio, 2020). Ainda segundo o mesmo dicionário, o termo "dissolvido" significa algo que se desfez, que foi diluído e até mesmo extinto (Aurélio, 2020). Além da definição proveniente do dicionário, a definição de consentimento presente na própria LGPD, em seu artigo 
$5^{\circ}$, inciso XII, define-o como "manifestação livre, informada e inequívoca pela qual o titular concorda com o tratamento de seus dados pessoais para uma finalidade determinada" (Lei n. 13.079, 2018). Desta forma, apresentamos nessa categoria os pontos dentro dos termos de consentimento da Uber que, ao conflitarem com a legislação de proteção de dados, podem ensejar uma redução da relevância do consentimento por parte do usuário.

Esta categoria é construída a partir de trechos como os três que são apresentados a seguir, encontrados nos termos de consentimento da Uber. Primeiro, nos Termos e Condições, no subitem "Do relacionamento contratual", em que a Uber afirma que "ao acessar e usar os Serviços você [usuário] concorda com os presentes termos e condições...." e que "Se você [usuário] não concorda com estes Termos, você não pode acessar nem usar os Serviços [da Uber].”, a organização vai contra a LGPD, em seu artigo 5, inciso XII. Neste trecho da lei, o consentimento é definido como a "manifestação livre, informada e inequívoca pela qual o titular concorda com o tratamento de seus dados pessoais para uma finalidade determinada". Desta forma, pela letra da lei, é possível entender que se faz obrigatório, para toda finalidade de tratamento dos dados pessoais do usuário, seu consentimento específico, não havendo a possibilidade de esse consentimento se dar por meio do simples uso do serviço, como afirma a organização em seu documento.

Segundo, ainda no documento da Uber nomeado Termos e Condições, no subitem "Do conteúdo fornecido pelo usuário", a empresa afirma que poderá efetuar diferentes práticas, desde sublicenciar até distribuir o conteúdo do usuário, inclusive com terceiros, "sem ulterior aviso a você [usuário] ou seu consentimento, e sem a necessidade de pagamento a você ou a qualquer outra pessoa ou entidade” (grifo nosso). Esse trecho do documento da Uber contraria, entre outros, o parágrafo $5^{\circ}$ do art. $7^{\circ} \mathrm{da} \mathrm{LGPD}$, segundo o qual, para o compartilhamento de dados pessoais com terceiros "[A empresa] deverá obter consentimento especifico do titular para este fim" (Lei n. 13.079, 2018, grifo nosso), e o inciso VII do artigo $7^{\circ}$ do Marco Civil da Internet, segundo o qual não é permitido "o fornecimento a terceiros de seus dados pessoais [do usuário] ... salvo mediante consentimento livre, expresso e informado...”. Desta forma, pela letra da lei, seria necessário que, para cada compartilhamento dos dados do usuário com terceiros, sejam parceiros ou empresas vinculadas à Uber, o mesmo usuário consentisse especificamente, não havendo espaço para consentimentos genéricos.

Terceiro, no documento nomeado como Políticas de Privacidade, o subitem "Alterações deste aviso" afirma que "Ocasionalmente, podemos alterar este aviso. Usar nossos serviços depois de uma alteração constitui um consentimento com o aviso alterado, até o limite permitido por lei." (grifo nosso). O trecho do documento da Uber sugere que, no caso de uma posterior alteração das Políticas de Privacidade, o fato de o usuário usar o serviço já constitui um consentimento, mesmo que este não ocorra efetivamente. Este trecho confronta ao menos sete dispositivos da LGPD (Art. $7^{\circ}$, inciso I, $\$ 5^{\circ}$ e $\$ 7^{\circ}$; Art. $8^{\circ}, \$ 3^{\circ}$ e $\$ 4^{\circ}$ e Art. $9^{\circ}, \$ 1^{\circ}$ e $2^{\circ}$ ) e dois dispositivos do Marco Civil da Internet (Art. $7^{\circ}$, incisos VIII e IX). A título de exemplo, o artigo $9^{\circ}$ da LGPD, em seu parágrafo $1^{\circ}$, garante ao usuário que as alterações do documento, neste caso, a Política de Privacidade, deverão ser "apresentadas previamente com transparência, de forma clara e inequivoca" (grifo nosso), pois, caso não o sejam, o consentimento "será considerado nulo". Além disso, o parágrafo $2^{\circ}$ do mesmo artigo $9^{\circ}$, determina que "o controlador [Uber] deverá informar previamente o titular sobre as mudanças de finalidade, podendo o titular revogar o consentimento, caso discorde das alteraçóes" (grifo nosso). Nesses casos relacionados à Política de Privacidade, observamos que a Uber, por meio de um Termo de Consentimento (neste caso, a Política de Privacidade) extingue a necessidade de permissão pelo usuário para que ela possa explorar seus dados.

\section{Compartilhamento irrestrito}

Segundo o dicionário Aurélio, o termo "compartilhamento" significa dividir, partilhar ou repartir, e tem em sua origem a união das palavras "com" mais o verbo "partilhar" (Aurélio, 2020). O mesmo dicionário atribui ao termo "irrestrito" o significado de não ter limites ou limitações ou aquilo que não está restrito (Aurélio, 
2020). Sob a lente jurídica, a própria LGPD, em seu artigo $5^{\circ}$, inciso XVI, define compartilhamento como “a comunicação, difusão, transferência e interconexão... de bancos de dados pessoais por órgãos e entidades públicos no cumprimento de suas competências legais, ou entre esses e entes privados, reciprocamente, com autorização específica. . "' (Lei n. 13.079, 2018). Neste contexto de organizações digitais são apresentados conflitos entre os dispositivos da Uber e a legislação que rege a proteção de dados dos usuários, em que a partilha dos dados coletados pela organização não é apresentada ao usuário detalhadamente.

Esta categoria pode ser observada em três diferentes trechos nos termos de consentimento da Uber. Primeiro, nos Termos e Condições, no subitem "Do conteúdo fornecido pelo usuário”, em que a Uber afirma que poderá "sublicenciar, usar, copiar, modificar, criar obras derivadas, distribuir, publicar, exibir, executar em público e, de qualquer outro modo, explorar esse conteúdo de usuário (a). . sem ulterior aviso a você ou seu consentimento. .." (grifo nosso), a organização sugere que poderá distribuir, publicar e exibir os dados do usuário sem o consentimento para tanto. Tal afirmação vai contra o parágrafo $7^{\circ}$ do art. $7^{\circ} \mathrm{da}$ LGPD, quando a lei afirma que "o tratamento posterior dos dados pessoais...poderá ser realizado para novas finalidades, desde que observados os propósitos legítimos e específicos para o novo tratamento e a preservação dos dados do titular..." (grifo nosso). De maneira semelhante, a mesma afirmação vai contra o artigo $7^{\circ}$, inciso VII do Marco Civil da Internet, que define ser direito do cidadão o "não fornecimento a terceiros de seus dados pessoais... salvo mediante consentimento livre, expresso e informado. .." (Lei n. 13.079, 2018, grifo nosso). Desta forma, ao não especificar com quais outras organizações os dados poderão ser compartilhados, sublicenciados e distribuídos, a Uber incorre em um desvio relacionado à LGPD e ao Marco Civil da Internet.

Segundo, no documento nomeado como Políticas de Privacidade, o subitem "Coleta e uso de dados" contém informações sobre a utilização dos dados dos usuários pela Uber. No tópico "dados de outras fontes”, os terceiros com quem a organização sugere o compartilhamento dos dados são definidos pelos termos Parceiros comerciais, Fornecedores, Provedores de seguro, Empresas de transporte parceiras e Prestadores de serviço de marketing. Com isso, observa-se uma possível incompatibilidades entre as disposições da Uber e o artigo $6^{\circ}$ da LGPD, em seus incisos I, III e VI. O inciso I descreve o princípio da finalidade, que determina que os objetivos a que se destina o tratamento de dados devem ser legítimos, específicos e informados ao titular desses direitos. O inciso III dispõe sobre o princípio da necessidade, segundo o qual o tratamento de dados pessoais deve se limitar à captação das informações estritamente necessárias para a concretização das finalidades propostas. Já o inciso VI descreve o princípio da transparência, de acordo com o qual os titulares dos dados pessoais têm o direito a informações claras, precisas e facilmente acessíveis sobre o tratamento e os agentes responsáveis por isso.

O terceiro exemplo foi localizado no documento nomeado Declaração de cookies: o subitem "Tipos e finalidades dos cookies" descreve como os cookies são usados pela organização. Ao descrever a forma de utilização dos dados para publicidade, o documento explica que as informações do usuário poderão ser utilizadas pela Uber e seus parceiros publicitários com o objetivo de "controlar a eficiência e desempenho campanhas publicitárias”, em uma prática nomeada "publicidade comportamental”. Entre esses parceiros são elencados Google, Facebook, Microsoft, Twitter, Yahoo, entre outros. Tais trechos do documento da Uber confrontam, assim como foi apresentado no exemplo anterior, a LGPD em seu artigo $6^{\circ}$, incisos I, III e VI, e o Marco Civil da Internet em seu artigo $7^{\circ}$, inciso VII.

Em resumo, os Termos de Consentimento apresentam, em diferentes pontos, práticas que podem levar o usuário a não compreender o grau de compartilhamento de seus dados com os parceiros da Uber. Além disso, o fato de a digitalização ser um processo que funciona, entre outros fatores, a partir do acúmulo e processamento de dados, pode dificultar a organização detalhar a forma como esse compartilhamento ocorre e com quais organizações, assim como explicar práticas como a publicidade comportamental. 


\section{Expropriação de dados}

Segundo o dicionário Aurélio, o termo "expropriação" significa excluir alguém da posse de uma propriedade, a apropriação daquilo que não lhe pertence e, ainda, a privação daquilo que pertence ao proprietário (Aurélio, 2020). Quanto ao termo "dados", o dicionário Aurélio atribui o significado a algo que pode ser processado e codificado por um computador (Aurélio, 2020).

Sob a lente da área jurídica, o termo "expropriar" trata de um instituto presente no artigo 1.228 do Código Civil, parágrafos $4^{\circ}$ e $5^{\circ}$, e que representa a tomada por um terceiro de algo pertencente ao indivíduo, atendidas determinadas condições de exceção (Lei 10.406, 2002; Ferreira \& Dos Santos, 2015). No caso aqui analisado, é importante, ainda, mencionar o significado atribuído por Srnicek (2019) aos dados, como uma informação sobre algo, alguém ou uma atividade, e que pode ou não envolver conhecimento.

Neste estudo, a presente categoria trata da apropriação pela Uber dos dados relacionados a comportamentos, decisões, sentimentos e preferências dos usuários. Por se tratar de um sistema complexo e que funciona a partir de complexos processos computacionais, nem sempre o usuário estará a par de todo o processo no qual seus dados estão envolvidos, podendo ensejar um sentimento de desconhecimento sobre o destino dos dados.

Essa categoria será exemplificada em dois diferentes trechos nos Termos de Consentimento da Uber. Primeiro, nos Termos e Condições, no subitem “Do conteúdo fornecido pelo usuário”, em que a Uber afirma que a licença abarcada no consentimento é

“. . . em nível mundial, perpétua, irrevogável, transferível, isenta de royalties, e com direito a sublicenciar, usar, copiar, modificar, criar obras derivadas, distribuir, publicar, exibir, executar em público e, de qualquer outro modo, explorar esse conteúdo de usuário ...sem ulterior aviso a você ou seu consentimento, e sem necessidade de pagamento a você ou a qualquer outra pessoa ou entidade.” Termos e condições, Uber, grifo nosso).

Este trecho do documento da Uber atribui à empresa uma ampla exploração dos dados dos usuários, sem o aviso ou consentimento.

Apesar de tal trecho buscar atender aos anseios da organização, tendo em vista que os dados são a base para seu funcionamento e aprimoramento de experiência do usuário, ele apresenta desvios relacionados aos artigos $7^{\circ}$, parágrafos $5^{\circ}$ e $7^{\circ}$, e o art. $9^{\circ}$, parágrafos $1^{\circ}$ e $2^{\circ}$ da LGPD. O parágrafo $5^{\circ}$ do art. $7^{\circ}$ da LGPD, descreve que, para o compartilhamento de dados pessoais com terceiros "(a empresa) deverá obter consentimento especifico do titular para este fim” (Lei n. 13.079, 2018, grifo nosso). Já o parágrafo $7^{\circ}$ determina que os dados pessoais podem ser utilizados para novas finalidades "desde que observados os propósitos legítimos e específicos para o novo tratamento". No parágrafo $2^{\circ}$ do art. $9^{\circ}$ é assegurada ao usuário a possibilidade de revogação do consentimento, a qualquer tempo, no caso deste usuário não ser informado previamente sobre "mudanças da finalidade para o tratamento de dados pessoais não compatíveis com o consentimento original".

A preocupação com a garantia de propriedade dos dados ao usuário também é percebida no parágrafo $1^{\circ}$ do art. $9^{\circ}$. Neste parágrafo, a lei manifesta que “o consentimento... será considerado nulo caso as informações fornecidas ao titular tenham conteúdo enganoso ou abusivo ou não tenham sido apresentadas previamente com transparência, de forma clara e inequívoca”. Desta forma, o trecho do documento da Uber mencionado neste momento confronta à LGPD ao atribuir à organização permissões que não são plenamente detalhadas ao usuário.

O segundo exemplo desta categoria foi verificado no documento da Uber nomeado como Políticas de Privacidade, especificamente nos subitens "Visão Geral" e "Coleta e uso de dados". Nestes subitens a Uber informa que poderá coletar "outros dados pessoais em conexão com nossa tecnologia e recursos de mapa" e receber "de terceiros dados demográficos sobre usuários". O fato de não especificar para o usuário os dados que serão coletados, pode caracterizar um desvio por parte da Uber, já que a legislação exige tal detalhamento. As disposições do documento da Uber apresentam termos genéricos como “outras coletas" e "outros dados", 
que pode ser um desvio frente ao direito à informação clara e inequívoca, de acordo com o art. $9^{\circ}, \$ 1^{\circ}$, sobre a utilização de seus dados.

Os exemplos apresentados até esse momento são uma parte dos mais de setenta pontos conflitantes entre os documentos relacionados aos termos de consentimento da Uber e a legislação de proteção de dados. Em seguida, tais conflitos são analisados à luz da teoria dos conceitos que permeiam o sistema de capitalismo de vigilância.

\section{Discussão}

Nesta etapa do artigo pretendemos responder às duas questões que orientaram esta pesquisa, a partir dos dados levantados entre os meses de janeiro e março de 2020, e do referencial teórico desenvolvido. Inicialmente, para responder à pergunta "Quais os tipos de desvios cometidos por uma organização da era do capitalismo de vigilância?”, faz-se necessário evidenciar que os documentos analisados advêm de uma construção unilateral, dentro da qual a organização busca adequar seus objetivos aos termos definidos pelo legislador ao compor as leis que compuseram a análise desse trabalho. A utilização do termo desvios devese ao fato de mais de cinquenta dispositivos dos Termos de Consentimento da Uber que conflitarem com a LGPD, e vinte dispositivos conflitarem com o Marco Civil da Internet, conforme apresentado nos resultados da pesquisa. Contudo, é importante ressaltar que a prática não configura um crime, mas uma decisão da organização que pode ser readequada mediante sua decisão ou a solicitação do órgão regulador.

Desta forma, a discussão evolui para a caracterização destes desvios. O desvio nomeado como má conduta (Vaughan, 1999) é caracterizado como atos ou omissóes que quebram ou rompem regras, leis ou regulamentos, com o objetivo de se obter um resultado de interesse da organização. Neste caso, diante do fato de o capitalismo de vigilância ter se tornado o modelo econômico dominante (Srnicek, 2017; Fuchs, 2017; Couldry \& Mejias, 2019; Zuboff, 2019) da era digital, os dados acabam sendo a riqueza deste modelo. Com isso, a organização aqui estudada, que está inserida nesse sistema, busca, por meio dos termos de consentimento, balancear seus interesses e o seu acesso aos dados dos usuários às prerrogativas legais. Contudo, esse tensionamento entre a organização prestadora de serviços plataformizados e a legislação vigente acabam gerando situações nas quais o consentimento acaba desgastado (Zarsky, 2019), seja pelas adequações que são feitas àquilo com o que o usuário concordou ou pelas exigências da própria legislação.

Essa prática não é nova e acompanha as relações entre as organizações modernas e seus stakeholders em uma disputa por recursos (Perrow, 1991), nesse caso, os dados. Dessa forma, ao desenvolver os termos de consentimento e apresentar situaçóes em que a organização pode processar dados dos usuários sem o seu consentimento específico, a organização está buscando acessar aqueles recursos que objetiva e, ao mesmo tempo, alcançar eficiência nesse procedimento. Tal situação foi observada, por exemplo, no documento Termos e Condições, subitem "Do relacionamento contratual”, em que a organização é autorizada a processar os dados dos usuários sem o seu consentimento específico para cada etapa do processo. Tal afirmação, à luz da teoria de má conduta, conflita, quebra ou rompe a regra presente no parágrafo $5^{\circ}$ do artigo $7^{\circ}$ da LGPD e o inciso IX do parágrafo $7^{\circ}$ do Marco Civil da internet, que exigem, explicitamente, o consentimento específico do usuário para qualquer finalidade em relação aos seus dados.

A categoria "expropriação de dados" também é caracterizada por desvios entre os dispositivos da Uber, a LGPD e o Marco Civil da internet. Por si só, expropriar significa privar o proprietário daquilo que ele possui ou excluí-lo da posse de uma propriedade sua. Ao utilizar os dados dos usuários sem que os caminhos percorridos em seus sistemas computacionais sejam detalhadamente apresentados ao proprietário desses dados, é possível inferir que o usuário é privado das informações sobre aquilo que lhe pertence. Dessa forma, a literatura acaba atribuindo aos sistemas das organizações plataformizadas e seus algoritmos termos como caixas pretas secretas (Pasquale, 2015; Venturini et al., 2016). 
Ao não conseguir informar ao titular dos dados quais são, exatamente, os "outros dados" ou "terceiros parceiros" envolvidos no processo de captação e processamento dos dados, observa-se um conflito com o inciso III do artigo $2^{\circ}$ da LGPD e parágrafo $1^{\circ}$ do artigo $9^{\circ}$, e com o inciso IX, do artigo $7^{\circ}$, do Marco Civil da Internet. Tais conflitos são exemplos alocados na categoria má conduta dos desvios, que apresentam problemas a serem solucionados pela organização adequando seus objetivos à legislação de proteção de dados.

Estes dois exemplos não são exaustivos, já que apresentamos nas próprias categorias dos resultados, outros exemplos que podem ser caracterizados, à luz da teoria de dark side da organização, como uma má conduta da Uber em relação aos dados de seus usuários. Sendo assim, passamos para a segunda pergunta que delineou esta pesquisa: Qual é o papel do Estado e das leis nesta atividade de expropriação que vivemos no capitalismo de vigilância?

A pergunta acima remete à afirmação da professora Soshana Zuboff de que as leis e regras poderiam trazer clareza e controlar os dispositivos desviantes dos termos de consentimento (Zuboff, 2019). Esse controle que a autora atribui às leis e regras podem desencadear diferentes reaçóes relacionadas aos processos e objetivos das organizações digitais, e aqui citamos três. A primeira reação seria um possível compartilhamento do poder que as organizações detêm na relação com seus usuários e com a sociedade em geral (Perrow, 1991), com os proprietários dos dados, desencadeando uma maior consciência sobre o processo no qual está inserido.

A segunda reação seria a maior nitidez sobre o desenvolvimento dos termos de consentimento e do funcionamento dos algoritmos aos quais os dados dos usuários são submetidos, em um modelo de compartilhamento de decisões entre organizações e usuários, ou de outros atores do ambiente políticoeconômico-social (Bijker, 1997; Michels \& Steyart, 2019; Flemming, 2019). A terceira reação seria uma eventual regulação dos fluxos dos dados dentro das plataformas digitais, demandando transparência dos processos algorítmicos e os possíveis retornos pecuniários (Srnicek, 2017; Couldry \& Mejias, 2019; Woodcock \& Graham, 2019). Trata-se de um conjunto de consequências que podem equilibrar o poder e o conhecimento sobre os processos que envolvem organizações, usuários e sociedade.

Esse tensionamento entre a proteção ao cidadão-usuário e aos seus dados e o poder e objetivo financeiro das organizações da era do capitalismo digital enseja uma participação do Estado no papel de protetor, propondo e fiscalizando leis. Essa perspectiva apresenta desafios na sociedade capitalista (Perrow, 1991; Alacadipani \& Medeiros, 2019), tendo em vista que o próprio sistema acaba, muitas vezes, aproveitando-se do papel do Estado e das leis para viabilizar novas formas de legitimação de seus objetivos, usualmente vinculados a resultados financeiros (Boltanski \& Chiapello, 2009; Chomsky, 2002).

As leis que analisamos aqui foram desenvolvidas com o objetivo de frear possíveis desvios e más-condutas relacionados à expropriação dos dados de usuários por organizações digitais, em um movimento inserido no contexto de darkside das organizações digitais. Contudo, por se tratar de um tema recente e uma nova configuração de capitalismo, observa-se uma atenção para a viabilidade técnica da legislação vigente e, ainda, uma dificuldade para fiscalizar seu cumprimento, evidenciando instabilidades e injustiças relacionadas à digitalização (Adler, Forbes \& Willmott, 2007; Cury, 2020). Dessa forma, o ambiente em que é tensionado o poder das organizações digitais plataformizadas e capilarizadas por todo o mundo e a proteção dos usuários e seus dados por uma lei vigente há pouco tempo acaba contribuindo para comportamentos desviantes (De Teffé \& De Moraes, 2017).

Respondendo, então, à pergunta da pesquisa, o papel do Estado e das leis é o de regular e fiscalizar a expropriação de dados dos indivíduos pelas organizações do capitalismo de vigilância por meio de Leis e mecanismos de fiscalização, como faz em outras áreas. Contudo, diante do rápido avanço das tecnologias de informação e comunicação e da recente formatação dos mecanismos de fiscalização e controle definidos, especialmente pela LGPD, são observadas práticas que podem ser caracterizadas como desviantes e más condutas. 


\section{Conclusão}

Este estudo buscou analisar as organizações do mundo digital a partir de uma abordagem crítica e privilegiar a análise de práticas que podem ser caracterizadas como inadequadas nas relações com seus stakeholders, resultando em assimetrias de poder e melhoria dos resultados financeiros e poder (Perrow, 1991; Alcadipani \& Medeiros, 2019). Este lado das organizações é nomeado como dark side ou lado obscuro, e desvela aquilo que está por trás de práticas identificadas pela própria empresa como adequadas (Vaughan, 1999).

A justificativa para tal análise repousa, especialmente, sobre dois fatores: primeiro, o fato de as organizações empresariais inseridas no sistema capitalista, assim como as organizações digitais, terem como principal objetivo o incremento de seus lucros, podendo levá-las a adotar práticas tecnicamente adequadas, mas eticamente desviantes (O’Neil, 2016; Morozov, 2018; Srnicek, 2019; Zuboff, 2019); e segundo, o fato de tais organizações contarem com uma legitimidade inerente às novas tecnologias dentro de uma sociedade tecnocrática e seus processos ainda serem uma caixa preta secreta (Pasquale, 2015; Couldry \& Mejias, 2019; Zuboff, 2019). Com isso, o objetivo desta pesquisa foi verificar qual o tipo de desvio que caracteriza o darkside das organizações digitais e como o Estado, por meio das leis, mobiliza-se nesta situação.

Para alcançar o objetivo do trabalho, desenvolvemos a análise de conteúdo dos termos de consentimento da Uber, da Lei 13.709 de 2018, chamada de Lei Geral de Proteção de Dados, a qual tem o propósito de proteger os cidadãos e seus dados nas relações do mundo digital, e da Lei 12.965 de 2014, chamada de Marco Civil da Internet, que estabelece princípios, garantias, direitos e deveres para o uso da internet no Brasil. A partir destas análises, confrontamos os dados dos documentos da Uber e das referidas leis, coletados entre os meses de janeiro e março do ano de 2020, verificando mais de setenta pontos de conflitos entre Leis e Termos de Consentimento. Tais conflitos se caracterizam dentro do conceito de dark sideda digitalização sob a alcunha de má conduta (Vaughan, 1999) devido ao fato de as ações da organização digital Uber não atenderem adequadamente às leis que regulam as relações entre os dados dos usuários e plataformas digitais.

No desenvolvimento desta investigação observamos que esse darkside da digitalização se apresenta em três diferentes aspectos: primeiro, os conflitos entre os termos de consentimento e as leis em mais de setenta pontos evidenciam um tensionamento entre a busca da organização pelos dados que podem ser usados para melhorar sua performance financeira e a necessidade de adequação à lei; segundo, o fato de os termos de consentimento orientarem as relações entre organizações e usuários, somado à necessidade da concordância pelos usuários para acessarem adequadamente os serviços, legitimam as práticas das organizações que compõem o capitalismo de vigilância. Nesse caso, é preciso atentar para o fato de que a necessidade de aceitação dos termos pelo usuário para viabilizar o acesso ao serviço ou à plataforma caracteriza-se como uma prática condenada pela LGPD. Terceiro, a recente vigência da LGPD e a morosidade que envolve um processo de viabilização de fiscalização e composição de órgãos responsáveis podem tornar-se fatores facilitadores da expropriação e exploração desviante dos dados dos usuários de plataformas geridas por organizações digitais.

As preocupações aqui apresentadas e, em especial, aquelas relacionadas aos possíveis desvios e más condutas por parte das organizações que compõem o sistema do capitalismo de vigilância não são exaustivas. Tendo em vista a rapidez com que as tecnologias mudam e são aprimoradas, pensamos que as organizações podem contribuir com o Estado no desenvolvimento de regras e artifícios de controle que busquem evitar expropriações desviantes e práticas que caracterizem a más condutas. Ao final do ano de 2021, a própria Uber apresentou aos seus usuários a possibilidade de terem as conversas gravadas ao longo das viagens. Tal prática tensiona uma possível apropriação de dados de voz e diálogos dos usuários e motoristas, ao passo que é apresentada como uma importante ferramenta de segurança. Além disso, eventuais situações que caracterizem desvios das organizações podem resultar em uma desconfiança por parte dos stakeholders, comprometendo a relação entre organização e usuários e clientes. 
Diante da digitalização das relações sociais e da tendência de as organizações, dentro de uma sociedade capitalista, buscarem sempre novas formas de se estruturar para garantir os melhores resultados financeiros e o poder, observamos que pesquisas sobre o tema são urgentes. Quanto às limitações do estudo, apontamos para o fato de acessarmos apenas os documentos de uma organização, o que se apresenta como um obstáculo para uma possível generalização a partir do presente estudo. Outra limitação está relacionada à observação do fenômeno do regramento da relação organizações e usuários por uma lente teórica ainda em formação. O trabalho seminal que orienta o conceito de capitalismo de vigilância é recente (Zuboff, 2019), assim como os principais trabalhos na área de organizações, apresentando tal situação como uma limitação, mas também como uma oportunidade para relevantes contribuiçóes. Para estudos futuros, faz-se necessária a análise crítica das práticas das organizações que mediam suas relações por plataformas digitais e, ainda, a interdisciplinaridade com áreas como o Direito, a Sociologia, a Psicologia e outras que auxiliem na compreensão das formas de exploração presentes nestas relações.

\section{REFERÊNCIAS}

Adler, P. S. (1992). Technology and the Future of Work. Oxford University Press on Demand.

Adler, P. S., Forbes, L. C., \& Willmott, H. (2007). 3 Critical management studies. Academy of management annals, I(1), 119-179.

Alcadipani, R., \& de Oliveira Medeiros, C. R. (2019). When corporations cause harm: A critical view of corporate social irresponsibility and corporate crimes. Journal of Business Ethics, 1-13.

André, R. G., da Silva, R. O., \& Nascimento, R. P. (2019). "Precário não é, mas eu acho que é escravo”: Análise do Trabalho dos Motoristas da Uber sob o Enfoque da Precarização. Revista Eletrônica de Ciência Administrativa, $18(1), 7-34$.

Andreassen, T. W., Lervik-Olsen, L., Snyder, H., Van Riel, A. C., Sweeney, J. C., \& Van Vaerenbergh, Y. (2018). Business model innovation and value-creation: the triadic way. Journal of Service Management.

Antunes, R. (2018). O privilégio da servidão: o novo proletariado de serviço na era digital. Boitempo editorial.

Bailey, J. (2008). First steps in qualitative data analysis: transcribing. Family practice, 25(2), 127-131.

Bardin, L. (2011). Análise de conteúdo. São Paulo: Edições 70.

Bijker, W. E. (1997). Ofbicycles, bakelites, and bulbs: Toward a theory of sociotechnical change. MIT press.

Boltanski, L., \& Chiapello, È. (2009). O novo espirito do capitalismo. WMF Martins Fontes.

Bond, R. M., Fariss, C. J., Jones, J. J., Kramer, A. D., Marlow, C., Settle, J. E., \& Fowler, J. H. (2012). A 61-millionperson experiment in social influence and political mobilization. Nature, 489(7415), 295-298.

Brandeis, L., \& Warren, S. (1890). The right to privacy. Harvard law review, 4(5), 193-220.

Charitsis, V., Zwick, D., \& Bradshaw, A. (2018). Creating worlds that create audiences: Theorising personal data markets in the age of communicative capitalism. tripleC: Communication, Capitalism \& Critique. Open Access Journal for a Global Sustainable Information Society, 16(2), 820-834.

Chomsky, N. (2002). O lucro ou as pessoas. Neoliberalismo e ordem global. Rio de Janeiro: Bertrand Brasil.

Constantiou, I. D., \& Kallinikos, J. (2015). New games, new rules: big data and the changing context of strategy. Journal of Information Technology, 30(1), 44-57.

Cornelissen, J., \& Cholakova, M. (2019). Profits Uber everything? The gig economy and the morality of category work. Strategic Organization, 1476127019894506.

Couldry, N. (2017). Surveillance-democracy. Journal of Information Technology \& Politics, 14(2), 182-188.

Couldry, N., \& Mejias, U. A. (2019). The costs of connection: How data is colonizing human life and appropriating it for capitalism. Stanford University Press.

Cowton, C. J. (1998). The use of secondary data in business ethics research. Journal of Business Ethics, 17(4), 423-434. 
Cramer, J., \& Krueger, A. B. (2016). Disruptive change in the taxi business: The case of Uber. American Economic Review, 106(5), 177-82.

Creswell, J. W., \& Creswell, J. D. (2017). Research design: Qualitative, quantitative, and mixed methods approaches. Sage publications.

Cury, M. E. (2020, maio, 14). Vigência da lei de proteção de dados é adiada devido ao coronavírus. Exame. Tecnologia. Disponível em: https://exame.abril.com.br/tecnologia/vigencia-da-lei-de-protecao-de-dados-e-adiada-devido-a o-coronavirus/.

da Costa Lage, M. L., \& Medeiros, I. (2019). QUANTO VALE? Farol-Revista de Estudos Organizacionais e Sociedade, 6(15), 13-16.

de Teffé, C. S., \& de Moraes, M. C. B. (2017). Redes sociais virtuais: privacidade e responsabilidade civil. Análise a partir do Marco Civil da Internet. Pensar-Revista de Ciências Jurídicas, 22(1), 108-146.

Elmholdt, K. T., Elmholdt, C., \& Haahr, L. (2021). Counting sleep: Ambiguity, aspirational control and the politics of digital self-tracking at work. Organization, 28(1), 164-185.

Feenberg, A. (2012). Questioning technology. Routledge.

Feenberg, A. (2017). Technosystem. Harvard University Press.

Ferreira, F. D., \& dos Santos, S. M. (2015). O direito à moradia urbana e a expropriação social no Código Civil de 2002. Revista de Direito da Cidade, 7(2), 437-467.

Fleming, P. (2019). Robots and organization studies: Why robots might not want to steal your job. Organization Studies, 40(1), 23-38.

Forgó, N., Hänold, S., \& Schütze, B. (2017). The principle of purpose limitation and big data. In New technology, big data and the law (pp. 17-42). Springer, Singapore.

Foster, J. B., \& McChesney, R. W. (2014). Surveillance capitalism: Monopoly-finance capital, the military-industrial complex, and the digital age. Monthly Review, 66(3), 1.

Franco, D. S., \& Ferraz, D. L. D. S. (2019). Uberização do trabalho e acumulação capitalista. Cadernos EBAPE. BR, $17(\mathrm{SPE}), 844-856$.

Fuchs, C. (2017). Social media: A critical introduction. Sage. Labor in Informational Capitalism and on the Internet

Ghani, N. A., Hamid, S., \& Udzir, N. I. (2016). Big Data and Data Protection: Issues with Purpose Limitation Principle. International Journal of Advances in Soft Computing \& Its Applications, 8(3).

Godoy, A. S. (1995). Pesquisa qualitativa: tipos fundamentais. Revista de Administração de empresas, 35(3), 20-29.

Kramer, A. D., Guillory, J. E., \& Hancock, J. T. (2014). Experimental evidence of massive-scale emotional contagion through social networks. Proceedings of the National Academy of Sciences, 111(24), 8788-8790.

Lei n. 10.406, de 10 de janeiro de 2002. Institui o Código Civil.

Lei n. 13.079, de 14 de agosto de 2018. Dispõe sobre a proteção de dados pessoais e altera a Lei $n^{\circ} 12.965$, de 23 de abril de 2014.

Lei n. 13.853, de 8 de julho de 2019. Altera a Lei no 13.709 , de 14 de agosto de 2018, para dispor sobre a proteção de dados pessoais e para criar a Autoridade Nacional de Proteção de Dados; e dá outras providências.

Medida Provisória n. 959 de 29 de abril de 2020. Estabelece...e prorroga a vacatio legis da Lei no 13.709, de 14 de agosto de 2018, que estabelece a Lei Geral de Proteção de Dados Pessoais - LGPD.

Projeto de Lei n. 5.762, de 30 de outubro de 2019. Altera a Lei no 13.709, de 2018, prorrogando a data da entrada em vigor de dispositivos da Lei Geral de Proteção de Dados Pessoais - LGPD - para 15 de agosto de 2022.

Langley, P. and Leyshon, A. (2017) 'Platform capitalism : the intermediation and capitalization of digital economic circulation.', Finance and society., 3 (1). pp. 11-31.

Linstead, S., Maréchal, G., \& Griffin, R. W. (2014). Theorizing and researching the dark side of organization. Organization Studies, 35(2), 165-188.

de Oliveira Medeiros, C. R., \& Alcapadipani, R. (2016). Nos bastidores corporativos, o sabor da vingança: Misbehaviour e humor como forma de resistência e subversão. Revista de Administração, 51(2), 123-136. 
MENDES, L. S. (2017). Dialogue between the Framework Internet Act and the Consumer Protection Code. Revista de Direito, 2017, 01-30.

Michels, C. \& Steyart, C. (2019). Bicycle as a mediating technology of organization. In: Beyes, T., Holt, R., \& Pias, C. (Ed.). The Oxford Handbook of Media, Technology, and Organization Studies. Oxford University Press.

Mittendorf, C. (2017). Create an Uber account? An investigation of trust and perceived risk in the sharing economy. Journal of Customer Behaviour, 16(3), 281-307.

Morozov, E. (2018). Big Tech. Ubu Editora LTDA-ME.

Mulder, T. (2019). Health apps, their privacy policies and the GDPR. European Journal of Law and Technology.

Obar, J. A., \& Oeldorf-Hirsch, A. (2018). The clickwrap: A political economic mechanism for manufacturing consent on social media. Social Media + Society, 4(3), 2056305118784770.

O'neil, C. (2016). Weapons of math destruction: How big data increases inequality and threatens democracy. Broadway Books.

O'reilly, T. (2009). What is web 2.0. " O'Reilly Media, Inc.".

Pasquale, F. (2015). The black box society. Harvard University Press.

Perrow, C. (1991). A society of organizations. Theory and society, 20(6), 725-762.

Sá-Silva, J. R., Almeida, C. D. D., \& Guindani, J. F. (2009). Pesquisa documental: pistas teóricas e metodológicas. Revista brasileira de história \& ciências sociais, 1(1), 1-15.

Shah, N. (2019). Interface. In: Beyes, T., Holt, R., \& Pias, C. (Ed.). The Oxford Handbook of Media, Technology, and Organization Studies. Oxford University Press.

Silva, A. O. D., \& Abdalla, M. M. (2020). Desenvolvimento? Para quem? Relações estratégicas entre empresa e sociedade: o lado obscuro da privatização da Companhia Siderúrgica Nacional (CSN). REAd. Revista Eletrônica de Administração (Porto Alegre), 26(1), 49-80.

Skok, W., \& Baker, S. (2019). Evaluating the impact of Uber on London's taxi service: A critical review of the literature. Knowledge and Process Management, 26(1), 3-9.

Srnicek, N. (2017). Platform capitalism. John Wiley \& Sons.

Stinchcombe, A. L. (1965). Social structure and organizations. Handbook of organizations, v. 7, p. 142-193, 1965.

Taplin, J. (2017). Move fast and break things: How Facebook, Google, and Amazon have cornered culture and what it means for all of us. Pan Macmillan.

Tomasevicius, E. Filho (2016). Marco Civil da Internet: uma lei sem conteúdo normativo. Estudos Avançados, 30(86), 269-285.

Trittin, H., Scherer, A. G., Whelan, G., \& Munro, I. (2019). Exploring dark and unexpected sides of digitalization: How digital technologies challenge organization and organizing. Call for papers: Special Issue of Organization, pp. 1-5.

Uber. (2020). Uber lança ferramenta de gravação de áudio. Uber Newsroom. Disponível em: https://www.uber.com/ $\mathrm{pt}-\mathrm{BR} /$ newsroom/uber-lanca-ferramenta-de-gravacao-de-audio/

Van Dijck, J. (2013). The culture of connectivity: A critical history of social media. Oxford University Press.

Vaughan, D. (1999). The dark side of organizations: Mistake, misconduct, and disaster. Annual review of sociology, 25(1), 271-305.

Venturini, J., Louzada, L., Maciel, M. F., Zingales, N., Stylianou, K., \& Belli, L. (2016). Terms of service and human rights: An analysis of online platform contracts. Rio de Janeiro, Brasil: Editora Revan.

Vianna, F. R. P. M., \& Meneghetti, F. K. (2020). Is it crowdsourcing or crowdsensing? An analysis of human participation in digital platforms in the age of surveillance capitalism. REAd. Revista Eletrônica de Administração (Porto Alegre), 26(1), 176-209.

Voigt, P., \& Von dem Bussche, A. (2017). The eu general data protection regulation (gdpr). A Practical Guide, 1st Ed., Cham: Springer International Publishing. 
WEF - World Economic Forum. (2019). Data science in the new economy: A new race for talent in the Fourth Industrial Revolution. Insight Report, pp. 1-22, 2019. Disponível em: http://www3.weforum.org/docs/WEF_ Data_Science_In_the_New_Economy.pdf.

Whelan, G. (2019). Born political: A dispositive analysis of Google and copyright. Business \& Society, 58(1), $42-73$.

Wood, A. J., Graham, M., Lehdonvirta, V., \& Hjorth, I. (2019). Good gig, bad gig: Autonomy and algorithmic control in the global gig economy. Work, Employment and Society, 33(1), 56-75.

Woodcock, J., \& Graham, M. (2019). The gigeconomy: a critical introduction. Polity.

Yoo, Y., Boland Jr, R. J., Lyytinen, K., \& Majchrzak, A. (2012). Organizing for innovation in the digitized world. Organization science, 23(5), 1398-1408.

Zarsky, T.Z. (2019). Privacy and manipulation in the digital age. Theoretical Inquiries in Law, 20(1), 157-188.

Zuboff, S. (2015). Big other: surveillance capitalism and the prospects of an information civilization. Journal of Information Technology, 30(1), 75-89.

Zuboff, S. (2019). The Age of Surveillance Capitalism: The Fight for a Human Future at the New Frontier of Power: Barack Obama's Books of 2019. Profile Books. 